\title{
Monocyte-Derived Suppressor Cells in Transplantation
}

\author{
Jordi Ochando $^{1} \cdot$ Patricia Conde $^{1} \cdot$ Vincenzo Bronte $^{2}$
}

Published online: 27 March 2015

(C) Springer International Publishing AG 2015

\begin{abstract}
Myeloid-derived suppressor cells (MDSC) are cells of myeloid origin with enhanced suppressive function. They are negative regulators of the immune responses and comprise a heterogeneous mixture of immunosuppressive cells of monocytic (M-MDSC) and granulocytic (G-MDSC) origin. A more recent nomenclature proposes the term "suppressive monocyte derived cells" (suppressive MCs) to define CSF1/ CSF2-dependent mouse suppressor cells that develop from common monocyte progenitors (cMoPs) after birth. Here, we review the literature about monocytic-derived cells with demonstrated suppressor function in vitro and in vivo within the context of solid organ transplantation.
\end{abstract}

Keywords MDSC $\cdot$ Suppressor MCs · Transplantation · Immune regulation

\section{Introduction}

The mononuclear phagocyte system (MPS) comprises monocytes, macrophages, and dendritic cells (DCs). The terminology to define cell subsets that belong to the MPS is currently confusing, and a new classification of macrophages,

This article is part of the Topical Collection on Cellular Transplants

Jordi Ochando

jordi.ochando@mssm.edu

1 Department of Medicine, Icahn School of Medicine at Mount Sinai, New York, USA

2 Department of Pathology and Diagnostics, Verona University Hospital, Verona, Italy monocytes, and DCs was recently proposed. In mice, two main subsets of monocytes $\left(\mathrm{Ly} 6 \mathrm{C}^{\mathrm{hi}} / \mathrm{CX} 3 \mathrm{CR} 1^{\mathrm{lo}}\right.$ and $\mathrm{Ly} 6 \mathrm{C}^{\mathrm{lo}} /$ CX3CR $1^{\text {hi }}$ ) [1]; three main subsets of DCs (BATF3 dependent cDC1, IRF4 dependent cDC2, and E2-2 dependent pDC) [2]; and various types of tissue resident macrophages that originate during embryogenesis (Kupffer cells-liver, microgliabrain, Langerhans cells - epidermis, alveolar macrophageslung) [3] have been defined. Upon inflammation, monocytes and DCs infiltrate the injured tissue and, along with the resident macrophages undergo activation, acquiring an inflammatory phenotype. This results in an overlapping expression of phenotypic markers, such as CD11c, F4/80, and MHC-II among these cell subsets, which makes it difficult to characterize specific myeloid cells under inflammatory conditions [4]. In an attempt to exploit immune regulatory mechanisms that take place during cancer progression and under other inflammatory pathological conditions, the term myeloidderived suppressor cells (MDSC) was originally proposed to describe $\mathrm{CD} 11 \mathrm{~b}^{+} \mathrm{Gr}-1^{+}$expressing myeloid cells with the ability to suppress the immune response [5]. The terminology was widely accepted by the research community, including transplant immunologists, which reported the critical implication of monocytic MDSC (M-MDSC) in the prolongation of allograft survival. A more recent nomenclature of the MPS has been proposed based on ontogeny, location, function, and phenotype [2]. This latest classification provides a criterion to define new myeloid subsets and recommends the term suppressive monocyte-derived cells (suppressive MCs) as CSF1/ CSF2-dependent suppressor cells that develop from common monocyte progenitors (cMoPs) after birth. Here, we provide a historical overview of monocyte-derived cells with demonstrated suppressive function in the context of solid organ transplantation. 


\section{Suppressive MCs in Solid Organ Transplantation}

Allograft immunological unresponsiveness is associated with presence of suppressor cells in the transplanted recipients, which include cells of the lymphoid and the myeloid lineage [6]. In solid organ transplantation, Nicholas Tilney and Terry Strom first suggested the suppressive activity of graft infiltrating, monocyte-derived cells in 1977 [7]. The suppressive capacity of acute rejecting and enhanced rat cardiac allograft infiltrating cells (in which macrophages account for $10 \%$ of the total) were analyzed by spontaneous blastogenesis using ${ }^{3} \mathrm{H}$-thymidine incorporation. Using fractionation approaches, the authors reported that the greatest suppressive activity corresponded to adherent cells of enhanced recipients $(90 \%)$, in contrast to non-adherent cells obtained from rejecting recipients (15\%) [7]. Further analysis of the adherent cells present in the spleen confirmed the above results, suggesting that monocyte-derived inflammatory macrophages, which accumulate in the enhanced allografts early after transplantation, possessed suppressive function.

In 1979, seminal work from Hyung Mo Lee and colleagues reported macrophage-related suppressor cell function in human renal transplant recipients $[8 \bullet]$. The study delineated the immune reactivity of cells obtained from 66 renal transplant recipients under routine immunosuppressive therapy with prednisone and azathioprine. The suppressive activity of mononuclear cells from renal transplant recipients was assayed by adding recipient mononuclear cells to donor stimulated, third-party cytotoxic $\mathrm{T}$ lymphocytes responding against ${ }^{51} \mathrm{Cr}$-labeled donor target cells. The percentage of lysis of target cells measured by ${ }^{51} \mathrm{Cr}$ release into the medium demonstrated that addition of mononuclear cells from renal transplant recipients suppressed cell-mediated lympholysis (CML) of donor cells in vitro. As controls for the suppressive function, the authors used non-donor fourth-party stimulated cytotoxic $\mathrm{T}$ lymphocytes and non-donor (recipient or irrelevant) ${ }^{51} \mathrm{Cr}$-labeled target cells, showing no suppressive activity. This experiment confirmed the antigen-specific suppressive function of transplant recipient mononuclear cells. Further, the authors went onto demonstrate that the adherent cell fraction of the mononuclear cells from renal transplant patients, containing 54-82\% esterase positive monocytes/macrophages, was responsible for the donor specific suppression.

Shortly afterwards, Judith and Francis Thomas extended their findings using an experimental skin allograft transplant model in rhesus monkey recipients that received a 5-day course of anti-thymocyte globulin (ATG) treatment [9]. The in vitro mitogen-induced lymphoproliferative response was reduced by the adherent fraction of the peripheral blood mononuclear cells (PBMC) from ATG-treated versus untreated rhesus monkeys skin allograft recipients. Both concanavalin A (Con A)- and phytohemagglutinin (PHA)-induced lymphocyte blastogenesis were reduced significantly when prostaglandin synthetase-dependent adherent cells were added to the cultures, suggesting that suppressive macrophages mediated part of the ATG induced immunosuppressive function. These experiments confirmed in vitro previous findings linking the immunosuppressive function of ATG with the ability of macrophages to phagocyte lymphocytes. In 1969, Ivan Roitt and colleagues reported that the immunosuppressive capacity of anti-lymphocyte sera (ALS) and its ability to prolong skin graft survival was associated with the capacity of macrophages to opsonize lymphocytes in vitro [10]. The authors reported that cytoadherence represented an early step in the process of opsonization, which suggested that the immunosuppressive function of ALS was in part due to macrophagemediated in vitro lymphocyte phagocytosis [11]. Similar results associated the suppressive function anti-lymphocyte globulin (ALG) with the rosette formation of lymphocytes around monocytes [12].

In 1983, an elegant study from Deborah Cameron further validated the suppressive function of macrophages present in transplant recipients [13]. Macrophages obtained from prednisone plus azathioprine treated human kidney transplant patients mediated cell cytotoxicity, as measured by release of ${ }^{3} \mathrm{H}-$ thymidine labeled target cells in vitro. Later in 1991, Kamada and colleagues reported two phases of cell-mediated suppressor activity, involving macrophages and regulatory $\mathrm{T}$ cells, respectively, in an experimental rat liver transplant model [14]. Early after transplantation (4-34 days), adherent suppressor macrophages present in the spleen of tolerant recipients mediated the in vitro inhibitory function measured by suppression of mixed leukocyte reactions, while late after transplantation (20 weeks), non-adherent suppressor $\mathrm{T}$ cells were responsible for the suppressive function of recipient splenic cells. Moreover, macrophage-mediated suppression was dependent on prostaglandins, since indomethacin inhibited their suppressive function [14]. These results suggested that non-specific suppressor macrophages develop in the spleens of tolerant liver transplant recipients.

The first report describing the suppressive activity of CD11b expressing monocytic cells was from by Myburgh and colleagues in 1995 [15]. Using non-human primates treated with total lymphoid irradiation as tolerogenic therapy, the authors characterized the antigen non-specific suppressor cells present in renal allograft recipients that inhibited in vitro mixed lymphocyte cultures. Depletion of CD11b or CD38 expressing cells resulted in loss of suppressive function of mononuclear cells obtained from the blood of transplanted baboons indicating that monocytes and NK cells mediated inhibition of cell proliferation. Suppression was mediated by a soluble factor, as inhibition of mixed lymphocyte cultures (MLC) separation of suppressor macrophages from responding $\mathrm{T}$ cells by a transwell cellulose membrane abrogated the in vitro suppressive activity. The authors went on to demonstrate that suppression was not mediated by PGE2 or by 
de novo protein synthesis since neither indomethacin nor cycloheximide had any effect on macrophage-mediated $\mathrm{T}$ cell hyporesponsiveness. On the contrary, the lysosomedestabilizing adjuvant Leu-Leu-OMe (LLOMe), which induces lysosome rupture, degradation of inflammatory proteins, and necrotic cell death, revealed that LLOMe treatment abrogated the macrophage inhibitory effect.

\section{MDSC in Solid Organ Transplantation}

Using the MDSC terminology [5], Vanhove and colleagues were the first to report the critical role of MDSC in solid organ transplantation using an experimental kidney transplant model in rats [16]. Tolerance was induced by a costimulatory blockade with anti $\mathrm{CD} 28$ antibodies and $\mathrm{CD} 11 \mathrm{~b}^{+} \mathrm{CD} 80 / 86^{+} \mathrm{Sirp} \alpha^{+}$ expressing MDSC cells accumulated in the recipient allografts. The $\mathrm{CD}_{11} \mathrm{~b}^{+}$Sirp $\alpha^{+}$expressing MDSC present in the blood and bone marrow inhibited proliferation of anti-CD3/ CD28 stimulated T cells in a contact-dependent manner, while the same cells obtained from the lymph nodes or the spleen did not. The suppressive mechanisms of tolerance was in part mediated by the inducible nitric oxide synthase (iNOS), since in vivo treatment with the iNOS inhibitor aminoguanidine abrogated tolerance in long-term allograft survival recipients $(<120$ days post-transplantation), and all grafts were rejected acutely. The critical role for iNOS in MDSC-mediated T cell suppression was reported by Segal and colleagues in experiments using inducible NO synthase knockout mice, which demonstrated that $\mathrm{NO}$ inhibited of $\mathrm{T}$ cell proliferation in an antigen-specific and cell contact-dependent manner [17]. In a separate report, Vanhove's laboratory demonstrated that graft infiltrating $\mathrm{CD}_{1} 1 \mathrm{~b}^{+} \mathrm{CD} 80 / 86^{+} \mathrm{Sirp} \alpha^{+}$expressing MDSC were responsible for the CCL5 gradient that directs Treg into the tolerized allograft during the induction of kidney allograft survival in rats [18].

In mice, MDSC express the cell surface markers CD11b (Mac-1) and Gr-1 [19, 20], and using these markers, Horuzsko and colleagues described a different mechanism by which MDSC mediated prolonged allograft survival [21]. Using an MHC-II mismatched bm12 skin transplants, which varies from its parental strain C57BL/6 at the I-A beta locus but are matched at all other major and minor histocompatibility antigens, the authors demonstrated that binding of HLA-G to the immunoglobulin-like transcript 2 (ILT-2) expressed in suppressive $\mathrm{CD} 11 \mathrm{~b}^{+} \mathrm{Gr}-1^{+}$expanded MDSC in vivo. This expansion was associated to indefinite allograft survival of MHC-II mismached skin graft recipients. The data is consistent with a previous report from Suciu-Foca and colleagues, which reported that expression of the ILT2/3 mice homologue paired immunoglobulin-like receptor B (PIR-B) in myeloid cells associated with prolonged allograft survival a rat transplant model [22].
Le Moine and colleagues reported the critical role of heme oxygenase-1 (HO-1) in MDSC-mediated alloreactivity suppression [23]. Using the skin transplant system described above (bm12 MHC-II disparate skin grafts into C57BL/6 recipients), the authors reported that in vivo treatment with LPS resulted in the development of HO- 1 expressing CD11 ${ }^{+}$GR$1^{+}$MDSC that produced large amounts of IL-10. These LPSinduced MDSC were able to inhibit polyclonally activated $\mathrm{CD}^{+}$and $\mathrm{CD}^{+} \mathrm{T}$ cell proliferation in an antigen-specific dependent manner. The authors went on to demonstrate that HO-1 inhibition abrogated and prevented IL-10 production by MDSC. Further, they demonstrated the potential therapeutic applications of MDSC in prolonging allograft survival using adoptive transfer experiments. This is to our knowledge the first report of MDSC transfer to unmanipulated recipients to prolong graft survival. These findings are consistent with previous reports suggesting the critical role of HO-1 in the modulation of IL-10 and the promotion of tolerance to transplanted organs. Bach and colleagues reported that, while long-term tolerance was not achieved in HO-1 deficient recipients, induction of HO-1 expression by cobalt protoporphyrin IX led to a significant up-regulation of Foxp3, TGF-beta, IL-10, and CTLA4 associated with prolonged graft survival [24]. Specific overexpression of HO-1 following adenovirus-mediated (AdHO-1) gene transfer has been reported to prolong graft survival [25].

In a mouse heart transplantation model under costimulatory blockade with anti-CD40L mAb, Ochando and colleagues demonstrated the tolerogenic role of MDSC in solid organ transplantation [26••]. Using different depletional approaches, including antibodies against Gr-1 and Ly6G, CD11b-DTR mice, Macrophage Fas-Induced Apoptosis (MAFIA) mice, and clodronate liposomes, the authors reported that transplantation tolerance was dependent on $\mathrm{CD} 11 \mathrm{~b}^{+} \mathrm{CD} 115^{+} \mathrm{GR}-1^{+}$ MDSC that migrated from the bone marrow to the transplant organ shortly after transplantation, where they prevented the initiation of adaptive immune responses that lead to allograft rejection and participated in the development of Tregs. The authors further proposed that both iNOS and arginase-1 (Arg1) mediated the suppressive function of monocytic $\mathrm{CD} 11 \mathrm{~b}^{+} \mathrm{CD} 115^{+} \mathrm{GR}-1^{+}$suppressive cells. MDSC use these enzymes to mediate their suppressive function, both of which are implicated in the L-arginine metabolism: iNOS, leading to suppressive NO production and Arg-1, which causes a direct starvation of arginine within the microenvironment [27]. This study is consistent with a previous report which demonstrated that CD115 expressing MDSC induced antigen-specific Treg expansion and iNOS dependent $\mathrm{T}$ cell suppression in tumorbearing mice [28].

Using a pancreatic islet transplantation in a diabetic mice, Bronte and colleagues described for the first time that organ rejection could be prevented by MDSC generated in vitro [29••]. Using a model of subcapsular islet transplantation in 
diabetic mice, the authors demonstrated that transfer of MDSC generated with GM-CSF and IL-6 inhibited $\mathrm{CD} 8^{+} \mathrm{T}$ cell priming and induced long-term acceptance of allogeneic islet allografts in the absence of immunosuppressive drug treatment. In the GM-CSF+IL-6 induced MDSCs treatment group, about $75 \%$ of mice remained normoglycemic and healthy for the entire observation period of 200 days, analogously to all the control mice transplanted with syngeneic islets. Graft histology indicated a histological pattern not compatible with insulitis in the MDSC-treated group and demonstrated that the lymphocytic infiltration (comprising $\mathrm{CD}^{+}$, $\mathrm{CD}^{+} \mathrm{T}$ cells, and $\mathrm{CD} 49 \mathrm{~b}^{+}$cells) was usually confined to the areas surrounding the insulin-positive graft. Tolerance was due the inhibition of IFN- $\gamma$ production by T cells and was dependent on the expression of CCAAT/enhancer-binding protein $\beta(\mathrm{C} / \mathrm{EBP} \beta)$, which regulates myelopoiesis during emergency myelopoiesis and has a crucial role in controlling the differentiation of myeloid progenitors to MDSC. This results have been recently confirmed by Louvet and colleagues, which evaluated the potential of GM-CSF/IL-6 and LPSinduced MDSC to control auto- and allo-immunity [30].

Using MHC class II disparate skin allograft model, Inverardi and colleagues demonstrated the ability of the colony-stimulating factor 3 (CSF3) to induce IL-4R $\alpha^{+}$MDSC in vivo following a short course of Neupogen treatment [31]. The authors further demonstrated that Neupogen mediated expansion of MDSC together with interleukin-2 complex (IL-2C) mediated expansion of Treg in vivo prolong allograft survival (MST $=74$ days). When looking into the mechanisms that were responsible for prolonged allograft survival, the authors indicated that synergistic treatment with Neupogen plus IL2-C resulted in an attenuated $\mathrm{T}$ cell response and reduction of cellular infiltrates into the allografts.

In addressing the involvement of alarmins in MDSC immunobiology, Thomson and Turnquist reported the crucial role for IL-33 in prolonging heart allograft survival in mice [32]. The authors demonstrated that IL-33 induces an increase in suppressive $\mathrm{CD} 11 \mathrm{~b}^{+} \mathrm{Gr}-1^{+} \mathrm{MDSC}$, together with an expansion of suppressive ST2 $2^{+} \mathrm{Foxp}^{+}$regulatory $\mathrm{T}$ cells in an ST2 (IL-1R-like-1)-dependent-manner in vivo. These findings revealed a new immunoregulatory activity of IL-33 with cardioprotective properties, as it limits ST2 expression and cardiovascular pathology. A recent report from this group confirms the potential role of IL-33 in the generation of activated IL-33R/ $\mathrm{ST} 2{ }^{+} \mathrm{ICOS}^{\text {high }} \mathrm{CD} 44^{\text {high }} \mathrm{Foxp}^{+}$Treg [33]. In human kidney transplant recipients, IL-33 represents an innate inflammatory mediator that activates iNK cells during ischemia reperfusion injury, and neutralization of IL-33 has been proposed as a potential therapeutic target [34]. These results contrast previous murine findings suggesting that IL-33 increase CD11bhigh Gr-1int MDSC that favors immune deviation, Foxp3+ Treg expansion, reduces antibody-mediated rejection, and prolongs allograft survival during acute and chronic cardiac rejection $[35,36]$.

An elegant study from Zhao and colleagues elucidated part of the signaling pathway mediated in iNOS-dependent prolongation of allograft survival mediated by MDSC [37]. $\mathrm{CD} 1 \mathrm{~b}^{+} \mathrm{Gr}-1^{+}$myeloid cells obtained from Smad3-deficient mice were shown to significantly inhibit alloantigen specific T cell responses, which resulted in a delayed allograft rejection in both skin and heart transplantation model in mice. These results reinforce the concept that transforming growth factor- $\beta$ (TGF- $\beta$ )/Smad3 signaling plays a complex role in the immune system, as TGF- $\beta$ directly suppresses both the clonal expansion of $\mathrm{CD} 8^{+} \mathrm{T}$ cells and their cell cytotoxicity in vivo [38]. The authors further demonstrated that Smad3-deficient MDSC were responsible for skewing T cells towards Th2-type immunity in transplanted Smad3-/- mouse recipients. Therefore, this study demonstrated that $\mathrm{Smad} 3$ is an intrinsic factor that inhibits the differentiation and immunosuppressive function of $\mathrm{CD} 11 \mathrm{~b}^{+} \mathrm{Gr}-1^{+}$MDSC in mouse transplant models.

Luo and colleagues reported that infusions of donor splenocytes treated with 1-ethyl-3(3'-dimethylaminopropyl)carbodiimide (ECDI-SPs) induced permanent donor-specific protection of islet allografts and prolonged cardiac allograft survival associated with intragraft accumulation of

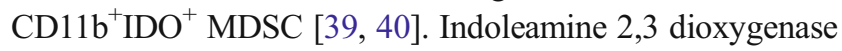
(IDO) activity limits T cell growth by depleting L-tryptophan and promotes $\mathrm{T}$ cell apoptosis by generating L-tryptophan-derived metabolites (i.e., kynurenins). Presence of intragraft $\mathrm{CD}_{1} 1 \mathrm{~b}^{+} \mathrm{IDO}^{+}$population was dependent on GR-1 ${ }^{+}$cells and either depletion of GR $-1^{+}$cells or inhibition of IDO activity abrogated graft protection by ECDI-SPs. Additionally, the authors reported that induction of tolerance is critically dependent on PD1/PDL1 signaling pathway, Foxp $3^{+}$Treg, and associated with increased IL-10 levels from in vitro stimulated T cells from ECDI-SPs treated recipients. In combination with a short course of rapamycin (day -1 to +8$)$ ECDI-SPs induced long-term allograft survival (>150 days) in $100 \%$ of the recipients. These results extend previous finding demonstrating that ECDI-fixed allogeneic splenocytes induced reduced CD8 $\mathrm{T}$ cell-mediated cytotoxicity in mixed lymphocyte reactions and in vivo CD4 T cell anergy [41, 42].

Lina $\mathrm{Lu}$ and colleagues reported the importance of stromal cells in the generation of graft protective MDSC [43]. Using an islet transplant model, the authors demonstrated that transfer of $\mathrm{CD}_{11 \mathrm{~b}^{+}}$and hepatic stellate cells (HSC) into the renal capsule of diabetic recipients differentiated $\mathrm{CD}_{1} 1 \mathrm{~b}^{+}$myeloid cells into potent MDSC that protected islet allograft and promoted long-term graft survival. MDSC protected the allografts by attenuating $\mathrm{CD} 8^{+} \mathrm{T}$ cell alloreactivity and promoting antigen-specific Treg cell development through the B7-H1 pathway. Both in vitro and in vivo data demonstrated that B7-H1 was required for MDSC to exert immune regulatory 
activity. The data extends previous findings from this group, which documented the induction of MDSC by HSC [44]. HSC-induced MDSC co-transplanted into the allografts expressed high levels of iNOS and Arg-1 and suppressed the proliferative response of both $\mathrm{CD} 4^{+}$and $\mathrm{CD} 8^{+} \mathrm{T}$ cells. Mechanistically, the authors showed that HSC lost their ability to induce MDSC when using HSC from IFN $\gamma \mathrm{R} 1$ deficient mice, and suggested that MDSC induction was mediated by soluble factors produced by HSC, such as complement 3 [45]. A recent report from this group reported the beneficial effects of GM-CS and HSC in the generation of iNOS ${ }^{+}$MDSC [46].

Strober and colleagues elucidated the cellular and molecular mechanisms by which a conditioning regimen with total lymphoid irradiation, anti-thymocyte serum (ATS), and donor bone marrow transplant induced the expansion of IL-4R $\alpha$ expressing MDSC that mediated the acceptance of cardiac allografts [47]. Specifically, the authors established that this conditioning regimen generates a tolerogenic environment with augmented numbers of IL-4R $\alpha$ expressing MDSC and IL-4 secreting iNKT. Using iNKT-deficient (CD1day ${ }^{-/-}$and $\mathrm{Ja} 18^{-/}$) and IL-4-deficient mice, the authors concluded that transplantation tolerance depended on MDSC-iNKT interaction and further implicated the possible role for Arg-1 in this clinically relevant conditioning regimen with the concomitant therapeutic applications. L-arginine is an amino acid essential for lymphocyte growth and differentiation, and depletion of Larginine through Arg-1 inhibits T cell proliferation. The critical role for IL-4R expressing MDSC and Arg-1 dependent T cell suppression was initially described by Bronte and colleagues, who demonstrated that arginase mediated suppression by IL-4R expressing MDSC required IL-4 [48]. These findings are consistent with Myburgh's report [15], which suggested an interplay between MDSC and NK in the establishment of transplantation tolerance mediated by total lymphoid irradiation as induction therapy [49].

In human kidney transplant recipients, Murphy and colleagues reported for the first time that $\mathrm{CD} 11 \mathrm{~b}^{+} \mathrm{CD} 33^{+} \mathrm{HLA}$ $\mathrm{DR}^{-}$MDSC were capable of expanding Treg in vitro and their accumulation after transplantation correlated with an increase in Treg in vivo [50•]. MDSC-dependent expansion of Treg was suggested to be mediated by the production of soluble factors such as TGF $\beta$ and IL10. Consistent with this hypothesis, it has been reported that human $\mathrm{CD} 14^{+} \mathrm{HLA}^{-} \mathrm{DR}^{\text {low/- }}$ MDSCs favor the development of Foxp $3^{+}$Treg through the production of TGF $\beta$ [51]. Interestingly, kidney transplant recipients of this study were treated with the synthetic corticosteroid prednisone. Glucocorticoids are given routinely to transplant recipient patients and induce IL-10 expression in $\mathrm{CD} 11 \mathrm{~b}^{+} \mathrm{Gr}-1^{+}$MDSC [52]. A recent report in mice by Liu and colleagues confirmed the above results and extended Sunderkoetter's findings to demonstrate that dexamethasone induced MDSC prolong skin allograft survival though glucocorticoid receptor, IL-10 and iNOS dependent manner $[49,53]$.

\section{Conclusions}

One of the major goals in solid organ transplantation is the induction of long-term allograft survival in a mature immune system that is free from chronic rejection and lifelong treatment with immunosuppressive drugs and their side effects. The use of MDSC in transplantation therapy is moving forward, and current literature indicates that MDSC favor allograft tolerance in many ways (Fig. 1 highlights MDSCdependent suppressive mechanisms that mediate graft survival). MDSC suppress inflammation and promote tissue repair in the allografts, exert immunosuppressive effects by secreting anti-inflammatory mediators, and induce alloantigen-specific Tregs, anergizing, and/or depleting recipient effector T cells. However, the complexity of the in vivo myeloid system in solid organ transplantation that regulates the immune response during strong sterile inflammatory conditions due to ischemia reperfusion injury of the donor organ and surgical anastomosis in the recipient makes it difficult to determine the specific mechanisms by which myeloid-derived subsets exert their inhibitory function. The original MDSC terminology includes multiple cell subsets as myelopoiesis refers to the differentiation of a myeloid progenitor into granulocytes, macrophages, mast cells, and dendritic cells. Myeloid cell subsets have been historically proposed based on morphology, cytochemistry, and flow cytometry, but the latest technological revolution in deep-sequencing, mass cytometry, and fate mapping experiments in vivo will enable us to classify myeloid cell subsets more appropriately. Using some of these novel approaches, Guilliams and collaborators have proposed the term monocyte-derived suppressive cells [2]. This recent classification may be more comprehensive in solid organ transplantation as it would include seminal studies from different laboratories that investigated the suppressive function of monocytederived cells. Hutchinson and colleagues reported the therapeutic potential of regulatory macrophages in human kidney transplant recipients and cardiac allograft transplanted mice

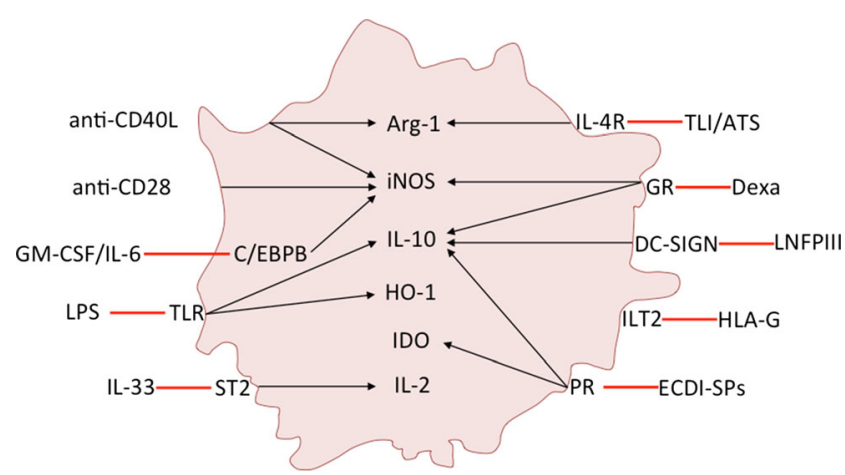

Fig. 1 Monocyte-derived suppressor cells in transplantation. The figure summarizes induction therapies and mechanisms of action of monocytederived suppressor cells in organ transplantation. $G R$ glucocorticoid receptor, $P R$ phagocytic receptor, TLI/ALS total lymphoid irradiation/antithymocyte serum 
([54•], [55••]), and Burlingham and colleagues reported graft survival prolongation using Lacto-N-fucopentaose III activated macrophages [56]. On the other hand, and in contrast to GMDSC depletional studies in tumor bearing mice [57], we demonstrated that depletion of Ly6G expressing granulocytic cells (clone A18) had no effect in tolerance, suggesting that only monocyte-derived cells are responsible for the induction of indefinite allograft survival in solid organ transplantation. In conclusion, clarification on how suppressive cells of the mononuclear phagocyte system are classified, consensus on which markers should be used for subset identification, and unified guidelines to characterize future suppressive cell subsets in solid organ transplantation is urgently needed.

Acknowledgments This work was supported by grants from the Italian Ministry of Health; Italian Ministry of Education (FIRB cup: B31J11000420001), Universities, and Research; Italian Association for Cancer Research (AIRC, grants 6599, 12182 and 14103) to Vincenzo Bronte and the Spanish Ministry of Education (SAF2013-48834-R) to Jordi Ochando.

\section{Compliance with Ethics Guidelines}

Conflict of Interest Jordi Ochando and Patricia Conde declare that they have no conflict of interest.

Vincenzo Bronte reports he has been a consultant/independent contract for Jounce Therapeutics Inc., and an advisor/board member for F. Hoffmann - La Roche LTD.

Human and Animal Rights and Informed Consent This article does not contain any studies with human or animal subjects performed by any of the authors.

\section{References}

Papers of particular interest, published recently, have been highlighted as:

- Of importance

•- Of major importance

1. Geissmann F, Jung S, Littman DR. Blood monocytes consist of two principal subsets with distinct migratory properties. Immunity. 2003;19(1):71-82.

2. Guilliams M, Ginhoux F, Jakubzick C, Naik SH, Onai N, Schraml BU, et al. Dendritic cells, monocytes and macrophages: a unified nomenclature based on ontogeny. Nat Rev Immunol. 2014;14(8): 571-8.

3. Perdiguero EG, Klapproth K, Schulz C, Busch K, Azzoni E, Crozet $\mathrm{L}$, et al. Tissue-resident macrophages originate from yolk-sac-derived erythro-myeloid progenitors. Nature. 2015;518(7540):547-51.

4. Ferenbach D, Hughes J. Macrophages and dendritic cells: what is the difference? Kidney Int. 2008;74(1):5-7.

5. Gabrilovich DI, Bronte V, Chen SH, Colombo MP, Ochoa A, Ostrand-Rosenberg $\mathrm{S}$, et al. The terminology issue for myeloid-derived suppressor cells. Cancer Res. 2007;67(1):425. author reply 426.

6. Furuzawa-Carballeda J, Lima G, Simancas P, Ramos-Bello D, Simancas M, Bostock IC, et al. Peripheral regulatory cells immunophenotyping in kidney transplant recipients with different clinical profiles: a cross-sectional study. J Transplant. 2012;2012: 256960.

7. Tilney NL, Strom TB, Booth DB, Finnegan A, Lundin P, Carpenter CB. Identification, cytotoxicity, and suppressor activity of infiltrating cells from enhanced organ allografts. Transplant Proc. 1977;9(1):713-5.

8. Thomas J, Thomas F, Hoffmann S, Johns C, Lee HM. Macrophagerelated suppressor cells in human renal transplant recipients. Surgery. 1979;86(2):266-74. This seminal manuscript provided the first evidence that long-term acceptance of histoincompatible allografts with an adaptation of the host immune response was mediated by suppressor macrophages that inhibited effector mechanisms of graft rejection.

9. Thomas JM, Carver FM, Haisch CE, Fahrenbruch G, Deepe RM, Thomas FT. Suppressor cells in rhesus monkeys treated with antithymocyte globulin. Transplantation. 1982;34(2):83-9.

10. Greaves MF, Tursi A, Playfair JH, Torrigiani G, Zamir R, Roitt IM. Immunosuppressive potency and in-vitro activity of antilymphocyte globulin. Lancet. 1969;1(7585):68-72.

11. Martin WJ. Assay for the immunosuppressive capacity of antilymphocyte serum. 3. Opsonizing activity of anti-human lymphocyte serum. J Immunol. 1969;103(5):1000-5.

12. Huber H, Michlmayr G, Fudenberg HH. The effect of antilymphocyte globulin on human monocytes in vitro. Clin Exp Immunol. 1969;5(6):607-17.

13. Cameron DJ. Macrophage mediated tumor cytotoxicity-function of macrophages in human renal allograft recipients. Jpn J Exp Med. 1983;53(1):19-26.

14. Yoshimura S, Gotoh S, Kamada N. Immunological tolerance induced by liver grafting in the rat: splenic macrophages and T cells mediate distinct phases of immunosuppressive activity. Clin Exp Immunol. 1991;85(1):121-7.

15. Gray CM, Smit JA, Myburgh JA. Identification of non-T suppressor cells with possible contra-interleukin-2 properties in non-human primates tolerant to their renal allograft. Afr J Health Sci. 1995;2(3):354-8.

16. Dugast AS, Haudebourg T, Coulon F, Heslan M, Haspot F, Poirier $\mathrm{N}$, et al. Myeloid-derived suppressor cells accumulate in kidney allograft tolerance and specifically suppress effector $\mathrm{T}$ cell expansion. J Immunol. 2008;180(12):7898-906.

17. Mazzoni A, Bronte V, Visintin A, Spitzer JH, Apolloni E, Serafini P, et al. Myeloid suppressor lines inhibit T cell responses by an NOdependent mechanism. J Immunol. 2002;168(2):689-95.

18. Dilek N, Poirier N, Usal C, Martinet B, Blancho G, Vanhove B. Control of transplant tolerance and intragraft regulatory $\mathrm{T}$ cell localization by myeloid-derived suppressor cells and CCL5. J Immunol. 2012;188(9):4209-16.

19. Bronte V, Apolloni E, Cabrelle A, Ronca R, Serafini P, Zamboni P, et al. Identification of a $\mathrm{CD} 11 \mathrm{~b}(+) / \mathrm{Gr}-1(+) / \mathrm{CD} 31(+)$ myeloid progenitor capable of activating or suppressing CD8(+) T cells. Blood. 2000;96(12):3838-46.

20. Bronte V, Wang M, Overwijk WW, Surman DR, Pericle F, Rosenberg SA, et al. Apoptotic death of CD8+ T lymphocytes after immunization: induction of a suppressive population of Mac-1+/ Gr-1+ cells. J Immunol. 1998;161(10):5313-20.

21. Zhang W, Liang S, Wu J, Horuzsko A. Human inhibitory receptor immunoglobulin-like transcript 2 amplifies CD11b+Gr1+ myeloidderived suppressor cells that promote long-term survival of allografts. Transplantation. 2008;86(8):1125-34.

22. Liu J, Liu Z, Witkowski P, Vlad G, Manavalan JS, Scotto L, et al Rat CD8+ FOXP3 + T suppressor cells mediate tolerance to allogeneic heart transplants, inducing PIR-B in APC and rendering the graft invulnerable to rejection. Transpl Immunol. 2004;13(4):239-47. 
23. De Wilde V, Van Rompaey N, Hill M, Lebrun JF, Lemaitre P, Lhomme F, et al. Endotoxin-induced myeloid-derived suppressor cells inhibit alloimmune responses via heme oxygenase-1. Am J Transplant. 2009;9(9):2034-47.

24. Yamashita K, Ollinger R, McDaid J, Sakahama H, Wang H, Tyagi $\mathrm{S}$, et al. Heme oxygenase-1 is essential for and promotes tolerance to transplanted organs. Faseb J. 2006;20(6):776-8

25. Braudeau C, Bouchet D, Tesson L, Iyer S, Remy S, Buelow R, et al. Induction of long-term cardiac allograft survival by heme oxygenase-1 gene transfer. Gene Ther. 2004;11(8):701-10.

26.• Garcia MR, Ledgerwood L, Yang Y, Xu J, Lal G, Burrell B, et al. Monocytic suppressive cells mediate cardiovascular transplantation tolerance in mice. J Clin Invest. 2010;120(7):2486-96. This is the first demonstration that monocyte-derived suppressor cells are required for the induction of transplantation tolerance.

27. Bronte V, Zanovello P. Regulation of immune responses by Larginine metabolism. Nat Rev Immunol. 2005;5(8):641-54.

28. Huang B, Pan PY, Li Q, Sato AI, Levy DE, Bromberg J, et al. Gr-1+ CD115+ immature myeloid suppressor cells mediate the development of tumor-induced $\mathrm{T}$ regulatory cells and T-cell anergy in tumor-bearing host. Cancer Res. 2006;66(2):1123-31.

29.• Marigo I, Bosio E, Solito S, Mesa C, Fernandez A, Dolcetti L, et al. Tumor-induced tolerance and immune suppression depend on the C/EBPbeta transcription factor. Immunity. 2010;32(6):790-802. This is the first demonstration that adoptive transfer of MDSC can be use in the absence of immunosuppressive therapy to induce transplantation tolerance.

30. Drujont L, Carretero-Iglesia L, Bouchet-Delbos L, Beriou G, Merieau E, Hill M, et al. Evaluation of the therapeutic potential of bone marrow-derived myeloid suppressor cell (MDSC) adoptive transfer in mouse models of autoimmunity and allograft rejection. PLoS One. 2014;9(6):e100013.

31. Adeegbe D, Serafini P, Bronte V, Zoso A, Ricordi C, Inverardi L. In vivo induction of myeloid suppressor cells and CD4(+)Foxp3(+) $\mathrm{T}$ regulatory cells prolongs skin allograft survival in mice. Cell Transplant. 2011;20(6):941-54.

32. Turnquist HR, Zhao Z, Rosborough BR, Liu Q, Castellaneta A, Isse $\mathrm{K}$, et al. IL-33 expands suppressive CD11b+ Gr-1(int) and regulatory T cells, including ST2L + Foxp3+ cells, and mediates regulatory $\mathrm{T}$ cell-dependent promotion of cardiac allograft survival. $\mathrm{J}$ Immunol. 2011;187(9):4598-610.

33. Matta BM, Lott JM, Mathews LR, Liu Q, Rosborough BR, Blazar $\mathrm{BR}$, et al. IL-33 is an unconventional Alarmin that stimulates IL-2 secretion by dendritic cells to selectively expand IL-33R/ST2 + regulatory T cells. J Immunol. 2014;193(8):4010-20.

34. Thierry A, Giraud S, Robin A, Barra A, Bridoux F, Ameteau V, et al. The alarmin concept applied to human renal transplantation: evidence for a differential implication of HMGB1 and IL-33. PLoS One. 2014;9(2):e88742.

35. Yin H, Li XY, Jin XB, Zhang BB, Gong Q, Yang H, et al. IL-33 prolongs murine cardiac allograft survival through induction of TH2-type immune deviation. Transplantation. 2010;89(10):118997.

36. Brunner SM, Schiechl G, Falk W, Schlitt HJ, Geissler EK, FichtnerFeigl S. Interleukin-33 prolongs allograft survival during chronic cardiac rejection. Transpl Int. 2011;24(10):1027-39.

37. Wu T, Sun C, Chen Z, Zhen Y, Peng J, Qi Z, et al. Smad3-deficient $\mathrm{CD} 11 \mathrm{~b}(+) \mathrm{Gr} 1(+)$ myeloid-derived suppressor cells prevent allograft rejection via the nitric oxide pathway. J Immunol. 2012;189(10):4989-5000.

38. Thomas DA, Massague J. TGF-beta directly targets cytotoxic T cell functions during tumor evasion of immune surveillance. Cancer Cell. 2005;8(5):369-80.

39. Luo X, Pothoven KL, McCarthy D, DeGutes M, Martin A, Getts DR, et al. ECDI-fixed allogeneic splenocytes induce donor-specific tolerance for long-term survival of islet transplants via two distinct mechanisms. Proc Natl Acad Sci U S A. 2008;105(38):14527-32.

40. Chen G, Kheradmand T, Bryant J, Wang S, Tasch J, Wang JJ, et al. Intragraft $\mathrm{CD} 11 \mathrm{~b}(+) \mathrm{IDO}(+)$ cells mediate cardiac allograft tolerance by ECDI-fixed donor splenocyte infusions. Am J Transplant. 2012;12(11):2920-9.

41. Corlett L, Davies DH. Reduced lysis by CD8+ cytotoxic T cells in mixed lymphocyte reactions induced via CD4+ T cells exposed to chemically modified antigen presenting cells. Immunology. 1995;84(3):488-94.

42. Karpus WJ, Peterson JD, Miller SD. Anergy in vivo: downregulation of antigen-specific CD4+ Th1 but not Th2 cytokine responses. Int Immunol. 1994;6(5):721-30.

43. Chou HS, Hsieh CC, Charles R, Wang L, Wagner T, Fung JJ, et al. Myeloid-derived suppressor cells protect islet transplants by B7-H1 mediated enhancement of $\mathrm{T}$ regulatory cells. Transplantation. 2012;93(3):272-82.

44. Chou HS, Hsieh CC, Yang HR, Wang L, Arakawa Y, Brown K, et al. Hepatic stellate cells regulate immune response by way of induction of myeloid suppressor cells in mice. Hepatology. 2011;53(3):1007-19.

45. Hsieh CC, Chou HS, Yang HR, Lin F, Bhatt S, Qin J, et al. The role of complement component $3(\mathrm{C} 3)$ in differentiation of myeloidderived suppressor cells. Blood. 2013;121(10):1760-8.

46. Arakawa Y, Qin J, Chou HS, Bhatt S, Wang L, Stuehr D, et al. Cotransplantation with myeloid-derived suppressor cells protects cell transplants: a crucial role of inducible nitric oxide synthase. Transplantation. 2014;97(7):740-7.

47. Hongo D, Tang X, Baker J, Engleman EG, Strober S. Requirement for interactions of natural killer $\mathrm{T}$ cells and myeloid-derived suppressor cells for transplantation tolerance. Am J Transplant. 2014;14(11):2467-77.

48. Bronte V, Serafini P, De Santo C, Marigo I, Tosello V, Mazzoni A, et al. IL-4-induced arginase 1 suppresses alloreactive $\mathrm{T}$ cells in tumor-bearing mice. J Immunol. 2003;170(1):270-8.

49. Liao J, Wang X, Bi Y, Shen B, Shao K, Yang H, et al. Dexamethasone potentiates myeloid-derived suppressor cell function in prolonging allograft survival through nitric oxide. J Leukoc Biol. 2014;96(5):675-84.

50. Luan Y, Mosheir E, Menon MC, Wilson D, Woytovich C, Ochando $\mathrm{J}$, et al. Monocytic myeloid-derived suppressor cells accumulate in renal transplant patients and mediate CD4(+) Foxp3(+) Treg expansion. Am J Transplant. 2013;13(12):3123-31. This is the first report that demonstrated that $C D 11 b+C D 33+H L A-D R$ - myeloid derived suppressor cells from human transplant recipients expand Treg in vitro and correlate with in vivo presence of Treg.

51. Hoechst B, Gamrekelashvili J, Manns MP, Greten TF, Korangy F. Plasticity of human Th17 cells and iTregs is orchestrated by different subsets of myeloid cells. Blood. 2011;117(24):6532-41.

52. Varga G, Ehrchen J, Tsianakas A, Tenbrock K, Rattenholl A, Seeliger S, et al. Glucocorticoids induce an activated, antiinflammatory monocyte subset in mice that resembles myeloidderived suppressor cells. J Leukoc Biol. 2008;84(3):644-50.

53. Ochando JC, Conde P. Editorial: Dexamethasone and MDSC in transplantation: yes to NO. J Leukoc Biol. 2014;96(5):669-71.

54. Riquelme P, Tomiuk S, Kammler A, Fandrich F, Schlitt HJ, Geissler $\mathrm{EK}$, et al. IFN-gamma-induced iNOS expression in mouse regulatory macrophages prolongs allograft survival in fully immunocompetent recipients. Mol Ther. 2013;21(2):409-22. This manuscript evaluates the ability of different in vitro generated macrophage subsets to prolong allograft survival in cardiac allograft recipient mice.

55.• Hutchinson JA, Riquelme P, Sawitzki B, Tomiuk S, Miqueu P, Zuhayra M, et al. Cutting edge: immunological consequences and trafficking of human regulatory macrophages administered to renal transplant recipients. J Immunol. 2011;187(5):2072-8. This is the 
first report investigating the clinical applications of regulatory macrophages as an adjunct immunosuppressive therapy in human kidney transplant recipients.

56. Dutta P, Hullett DA, Roenneburg DA, Torrealba JR, Sollinger HW, Harn DA, et al. Lacto-N-fucopentaose III, a pentasaccharide, prolongs heart transplant survival. Transplantation. 2010;90(10): 1071-8.

57. Srivastava MK, Zhu L, Harris-White M, Kar UK, Huang M, Johnson MF, et al. Myeloid suppressor cell depletion augments antitumor activity in lung cancer. PLoS One. 2012;7(7):e40677. 